\title{
BMJ Open Assessing medical student knowledge and attitudes about shared decision making across the curriculum: protocol for an international online survey and stakeholder analysis
}

Marie-Anne Durand, ${ }^{1}$ Renata Yen, ${ }^{1}$ Paul J Barr, ${ }^{1}$ Nan Cochran, ${ }^{1}$ Johanna Aarts, ${ }^{2}$ France Légaré, ${ }^{3}$ Malcolm Reed, ${ }^{4}$ A James O’Malley, ${ }^{1}$ Peter Scalia, ${ }^{1}$ Geneviève Painchaud Guérard, ${ }^{5}$ Glyn Elwyn ${ }^{1}$

To cite: Durand M-A, Yen $\mathrm{R}$, Barr PJ, et al. Assessing medical student knowledge and attitudes about shared decision making across the curriculum: protocol for an international online survey and stakeholder analysis. BMJ Open 2017;7:e015945. doi:10.1136/ bmjopen-2017-015945

- Prepublication history and additional material are available. To view these files please visit the journal online (http://dx.doi. org/10.1136/bmjopen-2017015945).

Received 11 January 2017

Revised 9 May 2017

Accepted 16 May 2017

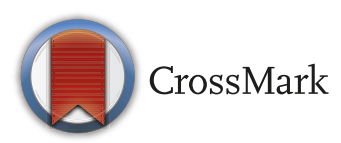

For numbered affiliations see end of article.

\section{Correspondence to}

Marie-Anne Durand;

marie-anne.durand@dartmouth. edu

\section{ABSTRACT}

Introduction Shared decision making (SDM) is a goal of modern medicine; however, it is not currently embedded in routine care. Barriers include cliniciansâ€ $€^{\mathrm{TM}}$ attitudes, lack of knowledge and training and time constraints. Our goal is to support the development and delivery of a robust SDM curriculum in medical education. Our objective is to assess undergraduate medical studentsâ€ ${ }^{\mathrm{TM}}$ knowledge of and attitudes towards SDM in four countries.

Methods and analysis The first phase of the study involves a web-based cross-sectional survey of undergraduate medical students from all years in selected schools across the United States (US), Canada and undergraduate and graduate students in the Netherlands. In the United Kingdom (UK), the survey will be circulated to all medical schools through the UK Medical School Council. We will sample students equally in all years of training and assess attitudes towards SDM, knowledge of SDM and participation in related training. Medical students of ages 18 years and older in the four countries will be eligible. The second phase of the study will involve semistructured interviews with a subset of students from phase 1 and a convenience sample of medical school curriculum experts or stakeholders. Data will be analysed using multivariable analysis in phase 1 and thematic content analysis in phase 2. Method, data source and investigator triangulation will be performed. Online survey data will be reported according to the Checklist for Reporting the Results of Internet E-Surveys. We will use the COnsolidated criteria for REporting Qualitative research for all qualitative data. Ethics and dissemination The study has been approved for dissemination in the US, the Netherlands, Canada and the UK. The study is voluntary with an informed consent process. The results will be published in a peer-reviewed journal and will help inform the inclusion of SDM-specific curriculum in medical education worldwide.

\section{INTRODUCTION}

Involving patients in medical decision making is considered an ethical imperative and a goal of modern medicine. ${ }^{2}$ Over the past
Strengths and limitations of this study

- We will conduct an international web-based, crosssectional survey of undergraduate medical students following Checklist for Reporting the Results of Internet E-Surveys and COnsolidated criteria for REporting Qualitative research guidelines.

- We followed a comprehensive, iterative survey development process that included several pilot phases.

- In order to determine when and how to deliver shared decision making training to medical students, this study will also include a stakeholder analysis of medical students and curriculum experts.

- Using convenience samples of medical schools in the USA, Canada and the Netherlands may introduce selection biases.

- Completion of the survey in English by Dutch undergraduate medical students may introduce biases and affect our ability to compare those data across participating countries.

decade, shared decision making (SDM) has demonstrated effectiveness in controlled contexts and garnered policy support worldwide. ${ }^{3}$ In the USA, the Patient Protection and Affordable Care Act encourages health organisations and healthcare professionals to promote patient engagement in healthcare and provide accessible, evidence-based information about the options' harms, benefits and outcome probabilities. ${ }^{45}$ According to the Institute of Medicine, patient participation in decision making should be promoted to improve the quality of healthcare. ${ }^{6}$ Since 2010, SDM has been featured prominently on the UK's policy agenda and actively promoted by the National Institute for Health and Care Excellence. ${ }^{78}$ In Canada, SDM initiatives are taking place in several provinces 
with health research funding available to support SDM research. ${ }^{39}$ In the Netherlands, the healthcare system has been reformed to promote patient-centred care, and various SDM research projects are underway. ${ }^{10}$

Despite proven benefits in controlled contexts, widespread adoption of SDM and related interventions is rare in routine clinical practice. ${ }^{311}$ Various barriers to the implementation of SDM have been identified. ${ }^{12-14}$ Time constraints, doctors' attitudes and lack of understanding about the relevance and applicability of SDM are major obstacles to widespread adoption. Time constraint was the most commonly reported concern preventing health professionals from practicing SDM. ${ }^{12}$ Eliciting patients' preferences and sharing decisions are often perceived to be more complex and time consuming than making a single treatment or screening recommendation. ${ }^{1516}$ There is no evidence, however, that SDM systematically increases consultation length. ${ }^{17}{ }^{18}$ Elwyn et al also described health professionals' indifference to decision support interventions and associated organisational inertia. ${ }^{16}$

In brief, SDM cannot become widespread unless clinicians fully understand the principles and benefits of SDM and are trained in communicating risks and engaging patients and significant others (caregivers and family) in deciding about their care. Research suggests that implementing SDM successfully in clinical practice will require interventions targeting the clinicians, the patients and, in the best of worlds, both. Effective interventions targeting clinicians include SDM training. ${ }^{19}$ SDM training thus needs to be increasingly embedded in continuing medical education. However, there is little evidence as to which strategies are most effective. ${ }^{20-22}$ Yet, continuing medical education is the tip of the iceberg. Training medical students in healthcare communication and SDM seems essential in facilitating routine adoption of SDM in the long term. However, to the best of our knowledge, there is no evidence that the principles of SDM are routinely taught in medical school curricula. Research into the knowledge and attitudes of medical students with regard to SDM is scarce. We have searched the literature, and evidence is also lacking as to when and how to teach SDM principles and skills in medical schools.

Studies of the attitudes of doctors in training towards patient-centred care suggest that patient-centredness tends to decline with medical education. Those studies assessed patient-centred care but did not specifically examine SDM. Patient-centred care can be defined as 'the importance of better understanding the experience of illness and of addressing patients' needs', ${ }^{23}$ and may or may not include SDM. SDM is: 'The process by which the optimal decision may be reached for a patient at a fateful health crossroads [...] and involves, at minimum, a clinician and the patient, although other members of the health care team or friends and family members may be invited to participate ${ }^{23}$ Research focusing on patient-centred care suggests that the more experienced medical students become, the less patient centred they are. $^{24-29}$ Although SDM is considered the pinnacle of patient-centred care ${ }^{30}$ it is unclear whether this apparent decline in patient-centredness also applies to SDM. A recent study of senior medical students in Peru revealed that the majority of students assessed their current consultation approach as 'paternalistic' or 'clinician-as-perfect agent'. ${ }^{31}$ Only $12 \%$ of the students reported adopting an SDM approach. ${ }^{31}$ The study did not assess students' knowledge of SDM and whether knowledge and attitudes about SDM differed according to medical education level. As far as can be determined, this is the only published study of medical students' attitudes towards SDM. ${ }^{31}$ Furthermore, there are no studies that have assessed SDM among medical students in English-speaking countries, or in countries where SDM has been promoted at the policy level. Consequently, our objectives are to:

1. investigate medical students' knowledge of and attitudes towards SDM across the medical curriculum in four countries, as well as their preferred consultation style (data primarily collected in phase 1 )

2. investigate the factors that may influence medical students' knowledge of and attitudes towards SDM (data collected in phases 1 and 2)

3. determine when and how to best deliver SDM training to medical students (data primarily collected in phase 2).

\section{METHODS AND ANALYSIS \\ Design and setting}

This is a multipronged study with two phases. Phase 1 will be a cross-sectional online survey of medical students across all years of medical education to determine their knowledge of and attitudes towards SDM conducted in the USA, UK, Canada and the Netherlands. We will report online survey data according to the Checklist for Reporting the Results of Internet E-Surveys (CHERRIES). ${ }^{32}$

Phase 2 will consist of semistructured telephone interviews with a purposive sample of medical students across the curriculum who have participated in phase 1 and with medical school curriculum experts or other relevant stakeholders (eg, education leads) ${ }^{33}$ to understand:

- whether there are specific needs for SDM training

- perceived barriers and facilitators to teaching SDM in the medical curriculum

- optimal format and timing of such training

- curriculum experts' knowledge of SDM.

We will report all qualitative data collected in phase 2 using the COnsolidated criteria for REporting Qualitative research. $^{34}$

\section{Participants}

Students

All undergraduate medical students registered at participating medical schools in the USA, UK, Canada and the Netherlands will be eligible for participation in phase 1 of this study. In Canada, we will include both Frenchspeaking and English-speaking medical students. In 
the Netherlands, we will also include graduate medical students within the first 6years of medical training. Students will be excluded if they are under the age of 18 years. We will also exclude residency programmes and foundation training in the UK. Including residents in this study would require a different recruitment strategy and additional time and resources. It is beyond the scope of the present study.

\section{Curriculum experts}

Curriculum experts or education leads are typically responsible for designing training programmes, developing and updating course content as well as coordinating learning curricula. Curriculum experts, education leads or other relevant stakeholders will be eligible for inclusion if they function in this role at one of the participating medical schools. In Canada, we will include French-speaking and English-speaking curriculum experts and will conduct the interviews in French or in English, according to each participant's preferred language.

\section{Recruitment}

For phase 1, all participants will be recruited via their medical school (eg, listservs and newsletters) or online advertisements (eg, student forums, Twitter, Facebook or student social media networks). Recruitment started in September 2016 and will end in May 2017. At some schools in Canada, the recruitment messages and survey will be available in French and in English. Participants will have the opportunity to take the survey in French or in English.

We will aim to recruit a minimum of 50 medical students per year of medical training, across all years of undergraduate medical education, per country. Given that the proposed survey is innovative, with no prior studies in a similar population using the same questionnaire and no prior validation, there is no known effect size on which to base the sample size calculation.

We have therefore used rules of thumb and existing literature indicating that 50 students per year of medical education is a reasonable and pragmatic sample size. ${ }^{35}$ This corresponds to 200 medical students recruited in the USA (ie, 4years of undergraduate medical education), 250 recruited in the UK (ie, 5 years of undergraduate medical education), up to 250 in Canada (ie, up to 5 years of undergraduate medical education) and 300 recruited in the Netherlands (ie, 6years of undergraduate medical education). In total, we aim to collect 1000 completed surveys. In order to facilitate recruitment, respondents will have the opportunity, at the end of the survey, to enter a prize drawing for a $\$ 20$ gift card ( 1 in 50 students entered into the prize draw will receive a gift card).

For phase 2, we aim to recruit both students and curriculum experts. Student participants will be a purposive sample from the phase 1 survey respondents who have indicated their willingness to take part in telephone semistructured interviews by providing their email addresses. Interviews are being conducted between March and June 2017. We will aim to interview students of different gender and ages from each participating country, in all years of medical education, with varying knowledge and attitudes of SDM and with or without prior SDM training. Telephone interviews will be conducted in English or French, according to the participant's preference. We will aim to recruit a representative sample of up to 12 students per country (up to 48 in total) or until data saturation is reached. ${ }^{33}$ The following stopping rule will be used: if no new information emerges after three consecutive interviews, no further interviews will be conducted. Students will be offered a $\$ 10$ gift card for their participation in these interviews. We will also contact a convenience sample of curriculum experts in each country and ask them to take part in a telephone semistructured interview. We will aim to recruit a sample of up to 12 curriculum experts per country (up to 48 in total). The same stopping rule, as mentioned above, will be applied for these interviews. The interview guides have already been drafted but will be revised and finalised building on the answers collected in phase 1 (see draft interview guide in online supplementary file 1).

\section{Data collection}

The following research questions will guide the data collected in phases 1 and 2 of the study:

1. What are medical students' knowledge of and attitudes towards SDM across the medical curriculum? (data primarily collected in phase 1)

2. Do knowledge of and attitudes towards SDM change with medical education? (data primarily collected in phase 1)

3. What are the potential factors that influence SDM during medical education? (data collected in phases 1 and 2)

4. How and when should SDM training be delivered during medical education? (data primarily collected in phase 2)

\section{Survey development}

The student survey (see online supplementary files 2 and 3 for English and French versions, respectively) comprises five sections:

1. Demographics;

2. Attitudes towards SDM derived from existing literature and the OPTION instrument ${ }^{36}$;

3. Clinical scenarios where each participant has to indicate: (A) how they see other clinicians (eg, attending physicians, residents and interns) make healthcare decisions and (B) how the student would react should they face this situation tomorrow (see box 1). The clinical scenarios were initially drafted by a Dartmouth fourth year medical student (MW). The first iteration was then revised and reworded by five of the authors, all experts in SDM, including two clinicians. The clinical scenarios section also includes one question on risk communication;

4. Knowledge of SDM derived from existing literature;

5. Previous SDM training. 


\section{Box 1 Clinical scenarios embedded in the survey}

\section{Clinical scenarios}

- A 45-year-old female presents to the emergency department. She requires an urgent emergency surgical intervention but is capable of giving consent.

- A 53-year-old male presents to his primary care physician for an annual physical exam. The patient asks his provider about the need to screen for colorectal cancer.

- A 40-year-old male with a family history of cancer A visits his physician to discuss undergoing a scheduled screening for cancer A. What is considered the most effective way of communicating how screening changes his risk of mortality from cancer $A$ ?

As far as could be determined from our review of the literature, there are no existing validated scales of students' attitudes towards and knowledge of SDM available in English. We therefore developed the items presented in the survey (see online supplementary file) using published literature, and discussion and consensus between study authors. The validated OPTION instrument was initially designed to assess the extent to which practitioners involve patients in decision-making processes. We used some of the OPTION items to assess students' attitudes to SDM as well as published studies about clinicians' attitudes to SDM.

The first iteration of the online survey was initially developed in 2013 and piloted in a small-scale online study conducted in the UK, recruiting medical students through online forums $(n=40)$. It was subsequently refined and reworded.

The second iteration of the survey was designed using Qualtrics software (Qualtrics). Qualtrics is an online survey platform that facilitates the creation and distribution of web-based surveys. Qualtrics maintains a high level of data security by using Transport Layer Security encryption for all transmitted data and servers protected with high-end firewall systems. ${ }^{37}$ We have set up a forced response for most questions in the survey, requiring that participants answer every content-based question with the option of 'I prefer not to say' for sensitive demographics questions. We have purposefully randomised the order of presentation of two sections of the survey, as highlighted in table 1 . The clinical scenario questions were randomised with the attitude questions to test if students' responses would change if they saw attitude questions before being presented with clinical-based questions. The survey uses skip logic (also known as adaptive questioning) to present information relevant to each country (eg, ethnicity categories and glossary of terms for non-native English speakers) according to the country selected by the participant in the demographics section. The number of questions per page varies from one to four. Table 1 provides additional detail on the survey outline. Each student completing the survey will see 19-23 questions. The approximate completion time is $10 \mathrm{~min}$.

The survey was piloted with a small convenience sample $(n=20)$ of medical students in years $1-4$, recruited at Geisel School of Medicine, Dartmouth College, in the spring of 2016. We used focus groups, brief interviews and online surveys to collect feedback about the usability and acceptability of the online survey, as well as the completion time. In accordance with CHERRIES, both the usability and technical functionality of the online survey were assessed. Changes made in this pilot phase included decreasing the number of clinical scenarios from five to three, changing the phrasing of some clinical scenario questions, adding additional questions regarding the length required to employ SDM, shortening and standardising the length of each answer choice for certain questions, adding the progress bar and adding the lottery-based monetary incentive for participation. In the Netherlands, the English survey was pilot tested by a group of 10 Dutch medical students (from years 3-6) for usability and applicability. The only major change arising from the pilot data collected in the Netherlands was the addition of a glossary defining potentially complex terms.

Table 1 Outline of survey questions per web page

\begin{tabular}{|c|c|c|}
\hline Page 1 & Language selection & 1 question \\
\hline Page 2 & Information sheet & No questions \\
\hline Page 3 & 'How do you think healthcare decisions should be made?' & 1 question \\
\hline Page 6 & Glossary of terms for Netherlands-based students & No questions \\
\hline Pages $7-10$ & Clinical scenarios, attitudes towards SDM (randomisation) & $\begin{array}{l}1-2 \text { questions per page, } 1 \text { page of } 6 \\
\text { statements with Likert-style response options }\end{array}$ \\
\hline Pages 15-17 & Awareness of SDM & $0-2$ questions per page* \\
\hline Pages 18-19 & Time needed for SDM & $0-1$ question per page* \\
\hline Page 20 & 'How do you think healthcare decisions should be made?' & 1 question \\
\hline Pages 21 and 22 & Email address/interview request & 0-1 question per page* \\
\hline
\end{tabular}

${ }^{*} 0$ questions indicates that a page would be skipped as a result of the respondents selection to previous questions. 
The first page of the survey asks the respondent to indicate their language of choice to complete the survey (English or French). The second page consists of a brief information sheet describing the study, its purpose and data protection policy. The information sheet intentionally does not mention SDM but uses the term 'health communication' to reduce potential respondent and desirability biases on the first question about healthcare decision making and scenarios. For questions assessing knowledge and attitudes towards SDM, we were forced to use the term SDM. The survey was translated from English to French by PS and reviewed by two authors (M-AD and GPG) who are both bilingual French/English speakers.

\section{Survey dissemination}

The survey is open but exclusively distributed to our target audience. No password protection is necessary to access the content. The initial contact with survey respondents is typically made on the internet (ie, using individual emails, a listserv or a web page).

In the UK, dissemination of the survey was initiated on 1 September 2016 to all 32 undergraduate medical schools through the UK Medical Schools Council. We will also advertise the survey on online forums and Facebook pages that are popular with medical students (eg, The Student Room, Student Doctor Network (UK \& Ireland) and medstudent.org).

In the USA and Canada, we have made direct contact with a convenience sample of four medical schools in each country. We were unable to distribute the survey to all US and Canadian medical schools using the Association of American Medical Colleges. Given our sample size requirements and the need to obtain ethical approval at school level in Canadian medical schools and in many American medical schools, we limited our sample to four schools in each country. Those medical schools were selected on the basis of existing contacts and school sizes. We will also advertise the web-based survey on online forums and social media pages that are popular with medical students (eg, Student Doctor Network, Student Doc Forum, doctorhangout.com, Canadian Federation of Medical Students and relevant Facebook groups). Data collection in those countries were initiated on 11 October 2016. One medical school in the USA and three schools in Canada started data collection between January and March 2017.

In the Netherlands, we followed the approach outlined for North America. Recruitment is occurring at four Dutch medical schools conveniently selected on the basis of existing contacts and geographical distribution. In addition, we will circulate the survey link to a national medical student association ('de Geneeskundestudent'). We will also advertise the online survey on popular student forums, relevant Facebook groups, Twitter and student networks. In the Netherlands, data collection was initiated on 1 October 2016.

We anticipate that data will be collected for 6 months in each country.

\section{Analysis}

We will include unique respondents only and will screen for the same respondent completing the survey multiple times using IP addresses.

For phase 1, we will use multivariable analysis to assess differences in knowledge and attitudes about SDM across the curriculum, within each country and between countries. Depending on the total number of completed surveys at each institution within each country, we will also attempt to assess differences in knowledge and attitudes about SDM between institutions. This might be possible in the USA, Canada and the Netherlands as four large medical schools have been approached but is unlikely to be achieved in the UK given all medical schools in the country have been approached.

In order to make the cross-country comparison equitable and meaningful, and given that undergraduate medical education ranges from four to 6years in the included countries, with variants regarding when the same content is taught or learnt, we will use the first year and the last year of medical education only. However, the within-country analysis will enable us to compare differences across all years of undergraduate medical education (up to 6 years), for each participating country. Depending on the total number of completed surveys at each institution within each country, we will also attempt to assess differences in knowledge and attitudes about SDM between institutions. This might be possible in the USA, Canada and the Netherlands as four large medical schools have been approached but is unlikely to be achieved in the UK given all medical schools in the country have been approached. For Canada, data collected in French will be analysed and reported separately.

We will also use an analysis of covariance to evaluate the influence of specific factors such as country, demographics, education level and previous training on knowledge and attitudes about SDM. To account for any changes in course contents over time, we will also include survey month as a control covariate in this analysis.

We plan to perform an analysis of the data after 6 months of online recruitment in each participating country. We hope that the primary findings will be based on this analysis. However, for practical reasons, should recruitment be slower than expected, we will continue data collection to obtain additional observations in which to test the validity of modelling assumptions and possibly obtain more precise inferences.

For phase 2, we will use a thematic analysis derived from descriptive phenomenology, ${ }^{38-40}$ assisted by the computer software ATLAS-ti (ATLAS-ti V.5.2). The transcripts will be coded according to all the themes discussed in the interviews, including spontaneously emerging themes. Similar codes will be merged and subsequently grouped into families of codes and networks. A proportion of transcripts chosen for being representative of the overall sample will be coded by two independent raters (M-AD and $\mathrm{RY}$ ) in order to ensure reliability of coding and to obtain consensus on the themes and family of 
codes for all remaining interview transcripts. Discrepancies among raters will be discussed until consensus is reached. Method, data source and investigator triangulation will be used. ${ }^{41}$ Method triangulation involves the use of multiple methods of data collection. In the context of the proposed study, we are collecting data using an online survey and semistructured interviews. Investigator triangulation consists of involving two or more researchers in the analysis of study data, thus bringing different perspectives to limit potential observers' bias and add breadth to the study findings. ${ }^{42}$ At least three researchers (M-AD, RY and $\mathrm{AJO}$ ) will be involved in data analysis. Finally, data source triangulation involves collecting data from different types of people: medical students across different levels of medical education and curriculum experts.

\section{ETHICS AND DISSEMINATION \\ Ethics}

This study is considered of minimal risk. The survey will be completed anonymously, and disclosure of sensitive personal information is not required of participants. The data obtained from the survey and interview will focus on participants' knowledge and opinions regarding SDM. We will ensure that all participants understand that the data we collect will remain anonymous and that their responses will be summarised without any identifying information.

In the USA, the study has been approved by Dartmouth College Committee for the Protection of Human Subjects (CPHS) for recruitment in all four countries (STUDY00029369). In the Netherlands, the Dartmouth CPHS approval was considered sufficient, given the minimal risk nature of the study, and no other ethics application process was required. In the UK, the study has been approved by the Brighton and Sussex Medical School Research Governance and Ethics Committee. In Canada, the study has been reviewed and approved by the ethics committee of the Universite Laval, University of Ottawa and McGill University. Université Laval was the multicentric evaluation committee, but ethics approval still needed to be sought from each participating medical school. In the USA, University of California, San Francisco requested that the study be reviewed and approved by their ethics board. University of Toronto, Washington University in St. Louis and Yale University accepted the Dartmouth CPHS approval as sufficient.

\section{Dissemination}

Results of the survey and semistructured interviews will be reported in a peer-reviewed journal. The research will also be presented at conferences and disseminated via social media. We also intend to share results with the Association of American Medical Colleges (AAMC) and the UK Medical School Council in order to influence the development of SDM curricula in medical education in those countries.
This study is the first to measure medical students' knowledge and attitudes about SDM in English-speaking countries, where SDM has been actively promoted but where clinician resistance and lack of understanding of SDM tenets and benefits have significantly limited its widespread adoption.

Understanding the factors that may influence knowledge and attitudes towards SDM to make SDM training particularly beneficial in the undergraduate medical curriculum will be invaluable. Understanding the perspective of the individuals who manage and coordinate medical education will contribute to determining how to increase the usability, acceptability and effectiveness of future SDM training.

\section{Author affiliations}

${ }^{1}$ The Dartmouth Institute for Health Policy and Clinical Practice, Dartmouth College, Lebanon, New Hampshire, USA

${ }^{2}$ Department of Obstetrics and Gynecology, Radboud University Medical Center, Nijmegen, The Netherlands

${ }^{3}$ Department of Family Medicine and Emergency Medicine, Université Laval, Quebec, Canada

${ }^{4}$ Department of Brighton and Sussex Medical School, Dean's Office, Brighton, UK ${ }^{5} \mathrm{CHU}$ de Québec Research Center, Saint-François d'Assise Hospital, Quebec, Canada

Correction notice This paper has been amended since it was published Online First. Owing to a scripting error, some of the publisher names in the references were replaced with 'BMJ Publishing Group'. This only affected the full text version, not the PDF. We have since corrected these errors and the correct publishers have been inserted into the references.

Acknowledgements We would like to thank Matthew Wesley for his contribution to the development of the clinical scenarios and support in recruiting medical students for the pilot study. We would also like to thank Tim Lahey, Brendin R. Beaulieu-Jones and the Geisel School of Medicine students who took part in the pilot study. We would also like to thank Drs Politi and Bussières for circulating the survey to medical students in their medical schools, and Drs Mills and Fortin for their help with ethics approval at University of California, San Francisco and Yale University. Finally, we would like to thank Julia Song for her help formatting and submitting the manuscript.

Contributors M-AD planned the study and designed the initial iteration of the survey. RY and M-AD developed the second iteration of the survey, in collaboration with PJB, NC and GE. RY obtained ethical approval in the USA and piloted the survey. JA facilitated the recruitment of medical schools in the Netherlands. MR obtained ethical approval in the UK and facilitated the recruitment of medical schools in partnership with the UK Medical School Council. FL and GPG facilitated the recruitment of medical schools in Canada and related ethical approval process, and translated materials into French. PS supported the ethical approval process in Canada and translation of materials into French. AJO provided guidance on the statistical analysis. M-AD and RY drafted the manuscript. All authors contributed to writing the manuscript and approved the final draft.

Funding This research received no specific grant from any funding agency in the public, commercial or not-for-profit sectors. France Légaré is Tier 1 Canada Research Chair in Shared Decision Making and Knowledge Translation.

Competing interests Financial: $M-A D$ is a consultant to Access Community Health Network, Chicago. GE has been a consultant to: (1) Emmi Solutions LLC who develop patient knowledge tools; (2) National Quality Forum on certification of patient knowledge tools; (3) Washington State Health Department on certification of patient knowledge tools; (4) PatientWisdom LLC, (5) SciMentum, Amsterdam, and (6) Access Community Health Network, Chicago. GE has edited / published books that provide royalties on sales by the publishers: the books have been on Shared Decision Making (Oxford University Press) and Groups (Radcliffe Press). NonFinancial: Many authors are authors of SDM and communication training programs in medical schools. However, they get no financial benefits from it. GE initiated and leads the Option Grid TM patient decision aids Collaborative, which produces and publishes patient knowledge tools in the form of comparison tables (http:// 
optiongrid.org/), and has part ownership of the registered trademark. GE owns copyright in CollaboRATE, IntegRATE, and Observer OPTION measures of shared decision making and care integration. These measures are freely available for use. PJB owns copyright in CollaboRATE.

Ethics approval Institutional Review Boards at Dartmouth College (USA), University of California San Francisco (USA), McGill University (Canada), Université Laval (Canada) and University of Ottawa (Canada). Brighton and Sussex Medical School Research Governance and Ethics Committee (UK).

Provenance and peer review Not commissioned; externally peer reviewed.

Open Access This is an Open Access article distributed in accordance with the Creative Commons Attribution Non Commercial (CC BY-NC 4.0) license, which permits others to distribute, remix, adapt, build upon this work non-commercially, and license their derivative works on different terms, provided the original work is properly cited and the use is non-commercial. See: http://creativecommons.org/ licenses/by-nc/4.0/

(C) Article author(s) (or their employer(s) unless otherwise stated in the text of the article) 2017. All rights reserved. No commercial use is permitted unless otherwise expressly granted.

\section{REFERENCES}

1. Mulley AG, Trimble C, Elwyn G. Stop the silent misdiagnosis: patients' preferences matter. BMJ 2012;345:e6572.

2 Oshima Lee E, Emanuel EJ. Shared decision making to improve care and reduce costs. N Engl J Med 2013;368:6-8.

3. Härter M, van der Weijden T, Elwyn G. Policy and practice developments in the implementation of shared decision making: an international perspective. Z Evid Fortbild Qual Gesundhwes 2011;105:229-33.

4. Charles C, Gafni A, Whelan T. Shared decision-making in the medical encounter: what does it mean? (or it takes at least two to tango). Soc Sci Med 1997;44:681-92.

5. Senate and House of Representatives. Patient Protection and Affordable Care Act. 2010

6. Institute of Medicine. Crossing the quality chasm: a new health system for the 21st century, 2001.

7. National Institute for Health and Care Excellence. Shared decision making. https://www.nice.org.uk/about/what-we-do/ourprogrammes/nice-guidance/nice-guidelines/shared-decision-making (accessed 5 Dec2016)

8. Department of Health. Equity and excellence: liberating the NHS 2010. https://www.gov.uk/government/uploads/system/uploads/ attachment_data/file/213823/dh_117794.pdf

9. Légaré F, Stacey D, Forest PG, et al. Moving SDM forward in Canada: milestones, public involvement, and barriers that remain. $Z$ Evid Fortbild Qual Gesundhwes 2011;105:245-53.

10. van der Weijden $\mathrm{T}$, van Veenendaal $\mathrm{H}$, Drenthen $\mathrm{T}$, et al. Shared decision making in the Netherlands, is the time ripe for nationwide, structural implementation? Z Evid Fortbild Qual Gesundhwes 2011:105:283-8.

11. Couët N, Desroches S, Robitaille H, et al. Assessments of the extent to which health-care providers involve patients in decision making: a systematic review of studies using the OPTION instrument. Health Expect 2015;18:542-61.

12. Gravel K, Légaré F, Graham ID. Barriers and facilitators to implementing shared decision-making in clinical practice: a systematic review of health professionals' perceptions. Implement Sci 2006;1:16.

13. Holmes-Rovner M, Valade D, Orlowski C, et al. Implementing shared decision-making in routine practice: barriers and opportunities. Health Expect 2000;3:182-91.

14. Légaré $\mathrm{F}$, Ratté $\mathrm{S}$, Gravel $\mathrm{K}$, et al. Barriers and facilitators to implementing shared decision-making in clinical practice: update of a systematic review of health professionals' perceptions. Patient Educ Couns 2008;73:526-35.

15. Elwyn G, Légaré $F$, van der Weijden $T$, et al. Arduous implementation: does the Normalisation process Model explain why it's so difficult to embed decision support technologies for patients in routine clinical practice. Implement Sci 2008;3:57.
16. Elwyn G, Scholl I, Tietbohl C, et al. "Many miles to go ...": a systematic review of the implementation of patient decision support interventions into routine clinical practice. BMC Med Inform Decis Mak 2013;13:14.

17. Légaré $F$, Thompson-Leduc P. Twelve myths about shared decision making. Patient Educ Couns 2014;96:281-6.

18. Stacey D, Légaré $F$, Col NF, et al. Decision aids for people facing health treatment or screening decisions. Stacey D, ed. Cochrane Database of Systematic Reviews. Chichester, UK: John Wiley \& Sons, Ltd, 2014.

19. Légaré F, Stacey D, Turcotte S, et al. Interventions for improving the adoption of shared decision making by healthcare professionals. Légaré F, ed. Cochrane Database of Systematic Reviews. Chichester, UK: John Wiley \& Sons, Ltd, 2014.

20. Towle A. Shifting the culture of continuing medical education: what needs to happen and why is it so difficult? $\mathrm{J}$ Contin Educ Health Prof 2000;20:208-18.

21. Allaire AS, Labrecque M, Giguere A, et al. What motivates family physicians to participate in training programs in shared decision making? J Contin Educ Health Prof 2012;32:98-107.

22. Légaré F, Politi MC, Drolet R, et al. Training health professionals in shared decision-making: an international environmental scan. Patient Educ Couns 2012;88:159-69.

23. Barry MJ, Edgman-Levitan S. Shared decision making--pinnacle of patient-centered care. N Engl J Med 2012;366:780-1.

24. Tsimtsiou Z, Kirana PS, Hatzichristou D. Determinants of patients attitudes toward patient-centered care: a cross-sectional study in Greece. Patient Educ Couns 2014;97:391-5.

25. Hook KM, Pfeiffer CA. Impact of a new curriculum on medical students' interpersonal and interviewing skills. Med Educ 2007;41:154-9.

26. Pfeiffer $\mathrm{C}$, Madray $\mathrm{H}$, Ardolino $\mathrm{A}$, et al. The rise and fall of students' skill in obtaining a medical history. Med Educ 1998;32:283-8.

27. Shankar PR, Dubey AK, Subish P, et al. Attitudes of first-year medical students towards the doctor patient relationship. JNMA J Nepal Med Assoc 2006;45:196-203-45.

28. Shankar PR, Dubey AK, Subish P, et al. Student attitudes towards the doctor-patient relationship in a medical college in western Nepal. Med Teach 2006;28:199.

29. Tsimtsiou Z, Kerasidou O, Efstathiou N, et al. Medical students' attitudes toward patient-centred care: a longitudinal survey. Med Educ 2007:41:146-53.

30. Weston WW. Informed and shared decision-making: the crux of patient-centered care. CMAJ 2001;165:438-9.

31. Zeballos-Palacios C, Quispe R, Mongilardi N, et al. Shared decision making in Senior Medical students. Medical Decision Making 2015;35:533-8.

32. Eysenbach G. Improving the quality of web surveys: the Checklist for Reporting results of internet E-Surveys (CHERRIES). J Med Internet Res 2004:6:e34.

33. Guest G, Bunce A, Johnson L. How many interviews are Enough?: an experiment with data saturation and variability. Field methods 2006;18:59-82.

34. Tong A, Sainsbury P, Craig J. Consolidated criteria for reporting qualitative research (COREQ): a 32-item checklist for interviews and focus groups. Int J Qual Health Care 2007;19:349-57.

35. Wilson Van Voorhis CR, Morgan BL. Understanding power and rules of thumb for determining Sample sizes. Tutor Quant Methods Psychol 2007;3:43-50.

36. Elwyn G, Hutchings $\mathrm{H}$, Edwards $\mathrm{A}$, et al. The OPTION scale: measuring the extent that clinicians involve patients in decisionmaking tasks. Health Expect 2005;8:34-42.

37. Qualtrics. Security Statement. 2016. https://www.qualtrics.com/ security-statement/ (accessed 8 Dec2016).

38. Denzin NK, Lincoln YS. Handbook of Qualitative Research. 2nd ed. Thousand Oaks, CA: SAGE Publications, Inc, 2000.

39. Holloway I. Qualitative research in Healthcare. 1st ed. Maidenhead, UK: Open University Press, 2005.

40. Pope C, Ziebland S, Mays N. Qualitative research in health care. analysing qualitative data. BMJ 2000;320:114-6.

41. Carter N, Bryant-Lukosius D, DiCenso A, et al. The use of triangulation in qualitative research. Oncol Nurs Forum 2014;41:545-7.

42. Denzin NK. Sociological methods: a sourcebook. New York, NY: McGraw-Hill, 1978. 